\title{
Laser autofluorescent microscopy of histological sections of parenchymatous biological tissues of the dead
}

\author{
O. G. Ushenko ${ }^{1}$, N. Syvokorovskaya ${ }^{2}$, V. Bachinsky ${ }^{2}$, O. Vanchulyak $^{2}$, \\ A.V. Dubolazov ${ }^{1}$, Yu.O. Ushenko ${ }^{1}$, A.Yu. Dovgun ${ }^{1}$ \\ ${ }^{1}$ Chernivtsi National University, 2 Kotsiubynskyi Str., Chernivtsi, Ukraine, 58012 \\ ${ }^{2}$ Bukovinian State Medical University, 3 Theatral Sq., Chernivtsi, Ukraine, 58000 \\ a.dubolazov@chnu.edu.ua
}

\begin{abstract}
The results of laser autofluorescence microscopy of the distribution of the intensity of the MLA of polycrystalline structures of biological tissue preparations are presented. The data of a statistical analysis of the distribution of the magnitude of the intensity of MLA networks of biological crystals of histological sections of tissues of the spleen and kidney with the parenchymal morphological structure of the dead with different levels of blood loss are presented.
\end{abstract}

Keywords: Laser autofluorescent microscopy, polycrystalline structures, pleen, kidney, blood loss.

\section{Functional diagram of multidimensional laser autofluorescence (MLA) microscopy of biological preparations}

In fig. 1 shown a functional block diagram of spectrally selective laser autofluorescence microscopy of parenchymal biological tissues $^{1-11}$.

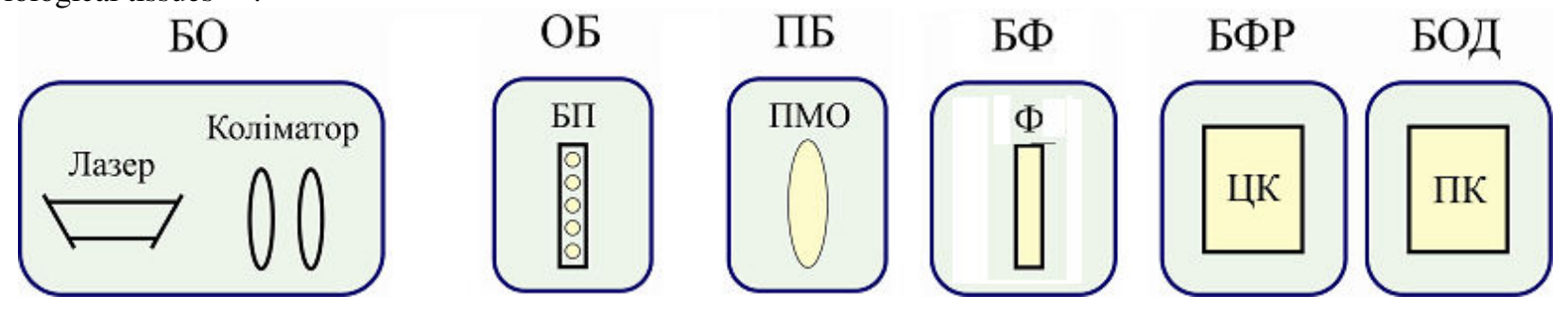

Fig. 1. Functional block diagram of multidimensional spectrally selective laser autofluorescence microscopy.

Here:

1 - the illumination block IB of biological preparations, which ensures the formation of a polarized laser beam parallel to $2 \mathrm{~mm}$ in diameter with a wavelength of $0.405 \mu \mathrm{m}$, which excites the intrinsic fluorescence of the fluorophores of biological preparations;

2 - the object block $\mathbf{O B}$ is a microscopic table with a two-coordinate movement on which the biological preparation BP is attached;

3 - projection block PB, which with the help of the micro-lens MO (4X) ensures the formation of an autofluorescent microscopic image of a biological preparation BP excited by a laser beam in the plane of the digital camera DC

4 - The block of spectral filtration of $\mathbf{B F}$, which includes the interference light filters $\mathbf{F}$ for the spectral selection of the excited aftholuorescent polychromatic radiation of an ensemble of BP fluorophores;

5 - a block of photoelectron registration BFR of microscopic fluorescent images of biological preparations BP, which includes the $\mathbf{C C}$ and provides the formation of the coordinate digital distribution of the intensity value in the computer interface;

6 - a data processing block DPB that, using a personal computer PC, provides a calculation of the magnitude of the statistical moments of the 1st to 4th orders characterizing the intensity distribution of the spectrally selective autofluorescence of biological preparations BP.

Fourteenth International Conference on Correlation Optics, edited by

Oleg V. Angelsky, Proc. of SPIE Vol. 11369, 113691V · (c) 2020 SPIE

CCC code: $0277-786 X / 20 / \$ 21 \cdot$ doi: $10.1117 / 12.2553973$ 


\section{Samples}

Depending on the level of blood loss, the following groups of samples of histological sections of the spleen and kidney with the subsequent level of blood loss were considered: $V=0 \mathrm{Mn}^{3}$ - group 1 (samples); $V=500 \mathrm{Mu}^{3} \pm 100 \mathrm{Mu}^{3}$ - group 2 (samples); $\quad V=1000 \mu^{3} \pm 100 \mu^{3}$ - group 3 (samples); $V=1500 \mu^{3} \pm 100 \mu \mu^{3} \quad$ - group 4 (samples); $V=2000 \mu^{3} \pm 100 \mu^{3}$ - group 5 (samples ); $V=2500 \mu^{3} \pm 100 \mu \mu^{3} \quad$ - group 6 (samples) ..

On a series of fragments of fig. 2 shown the experimentally determined coordinate distributions (fragments (1), (3)) and histograms (fragments (2), (4)) random values of the fluorescence intensity of the parenchymal structure of histological sections of the spleen of the dead from group 1 (fragments (1), (2)) and groups 3 (fragments (3), (4)).
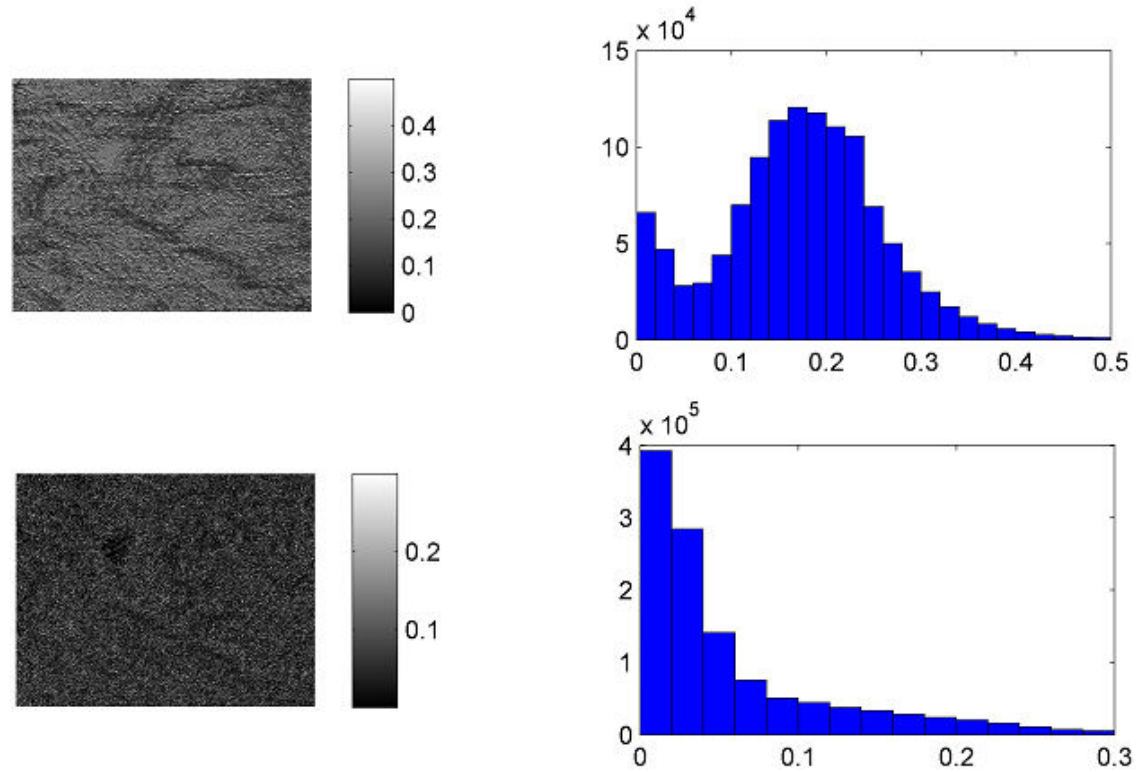

Fig. 2. Maps ((1), (3)) and histograms ((2), (4)) distributions of the autofluorescence intensity values of histological sections of the spleen of the control ((1), (2)) and research ((3), (4)) groups the dead.

Quantitatively, the scenario of changes in the fluorescent properties of an ensemble of blood cells of the parenchymal structure of the histological sections of the spleen of the dead with varying degrees of blood loss is illustrated by the statistical moments ${ }^{12-17}$ of the 1 st - 4th orders given in Table 1.

Table 1. The statistical structure of the autofluorescence intensity maps of histological sections of the spleen of the dead with varying degrees of blood loss

\begin{tabular}{|c|c|c|c|}
\hline Blood loss, $\mathrm{mm}^{3}$ & 0 & $500 \pm 100 \mathrm{~mm}^{3}$ & $1000 \pm 100 \mathrm{~mm}^{3}$ \\
\hline The average, $S M_{1}$ & $0.17 \pm 0.007$ & $0.14 \pm 0.006$ & $0.11 \pm 0.0045$ \\
\hline Criteria, $t, p$ & $p \prec 0.05$ & $p \prec 0.05$ & $p \prec 0.05$ \\
\hline Dispersion, $S M_{2}$ & $0.09 \pm 0.004$ & $0.07 \pm 0.003$ & $0.055 \pm 0.002$ \\
\hline Criteria, $t, p$ & $p \prec 0.05$ & $p \prec 0.05$ & $p \prec 0.05$ \\
\hline Asymmetry, $S M_{3}$ & $0.25 \pm 0.011$ & $0.75 \pm 0.034$ & $1.22 \pm 0.058$ \\
\hline Criteria, $t, p$ & $p \prec 0.05$ & $p \prec 0.05$ & $p \prec 0.05$ \\
\hline Excess, $S M_{4}$ & $0.72 \pm 0.029$ & $1.11 \pm 0.051$ & $1.53 \pm 0.069$ \\
\hline Criteria, $t, p$ & $p \prec 0.05$ & $p \prec 0.05$ & $p \prec 0.05$ \\
\hline Blood loss, $\mathrm{mm}^{3}$ & $1500 \pm 100 \mathrm{~mm}^{3}$ & $2000 \pm 100 \mathrm{~mm}^{3}$ & $2500 \pm 100 \mathrm{~mm}^{3}$ \\
\hline The average, $S M_{1}$ & $0.09 \pm 0.004$ & $0.07 \pm 0.003$ & $0.04 \pm 0.002$ \\
\hline Criteria, $t, p$ & $p \prec 0.05$ & $p \prec 0.05$ & $p \prec 0.05$ \\
\hline
\end{tabular}




\begin{tabular}{|c|c|c|c|}
\hline Dispersion, $S M_{2}$ & $0.045 \pm 0.002$ & $0.032 \pm 0.001$ & $0.025 \pm 0.001$ \\
\hline Criteria, $t, p$ & $p \prec 0.05$ & $p \prec 0.05$ & $p \prec 0.05$ \\
\hline Asymmetry, $S M_{3}$ & $1.77 \pm 0.075$ & $2.02 \pm 0.096$ & $2.31 \pm 0.11$ \\
\hline Criteria, $t, p$ & $p \prec 0.05$ & $p \prec 0.05$ & $p \prec 0.05$ \\
\hline Excess, $S M_{4}$ & $1.96 \pm 0.098$ & $2.34 \pm 0.11$ & $2.88 \pm 0.13$ \\
\hline Criteria, $t, p$ & $p \prec 0.05$ & $p \prec 0.05$ & $p \prec 0.05$ \\
\hline
\end{tabular}

Established:

- the range of changes in the magnitude of the 1 st to 4 th order statistical momentum, which characterizes the distribution of the intensity of MLA in the parenchymal structures of the histological sections of the spleen, by volume of blood loss is $0 \mathrm{~mm}^{3} \div 2500 \mathrm{~mm}^{3}$ :

- the average magnitude $S M_{1}$ varies within the range of averages from 0.17 to 0.04 ;

- the dispersion magnitude $S M_{2}$ varies the range of averages from 0.09 to 0.025 ;

- the asymmetry magnitude $\mathrm{SM}_{3}$ varies the range of averages from 0.25 to 2.31 ;

- the excess magnitude $\mathrm{SM}_{4}$ varies the range of averages from 0.72 to 2.88 .

In fig. 3 shows diagrams of changes in the magnitude of the statistical moments characterizing the distribution of the magnitude of the laser autofluorescence intensity of histological sections of the spleen as a result of the blood loss of all groups of the deceased.

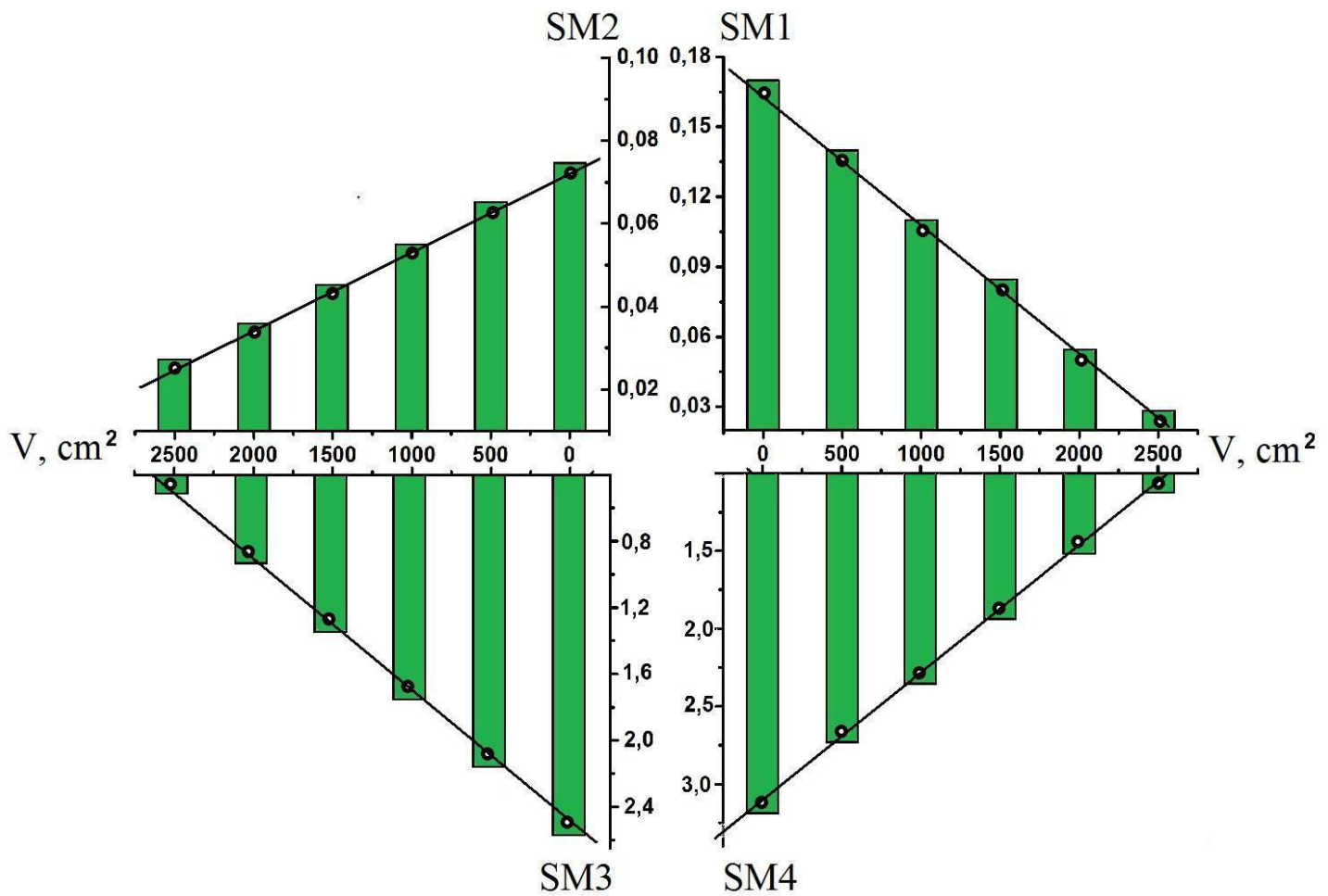

Fig. 3. Dependencies of the magnitude of the average (1), dispersion (2), asymmetry (3) and excess (4), which characterize the autofluorescence intensity maps of histological sections of the spleen of the deceased with varying degrees of blood loss.

The results of the method of spectral-selective laser autofluorescence microscopy (Fig. 3) show that the dynamics of changes in the magnitude of the statistical moments (average (1), dispersion (2), asymmetry (3) and excess (4)) characterizing the distribution of the fluorescence blood elements histological sections of the spleen of the dead, vary 
within the volume of blood loss $0 \mathrm{~mm}^{3} \div 2500 \mathrm{~mm}^{3}$. The most sensitive to MLA parenchymatous structures of histological sections of this organ to statistical parameters of the 2nd to 4th orders were established.

\section{The effectiveness of the differential diagnosis of the degree of blood loss by laser autofluorescence microscopy}

For each statistical moment that characterizes the distribution of the MLA intensity values of a set of spleen samples from different groups of deceased, the accuracy of determining the blood loss volume was found on the basis of a series of nomograms presented in fig. 4.

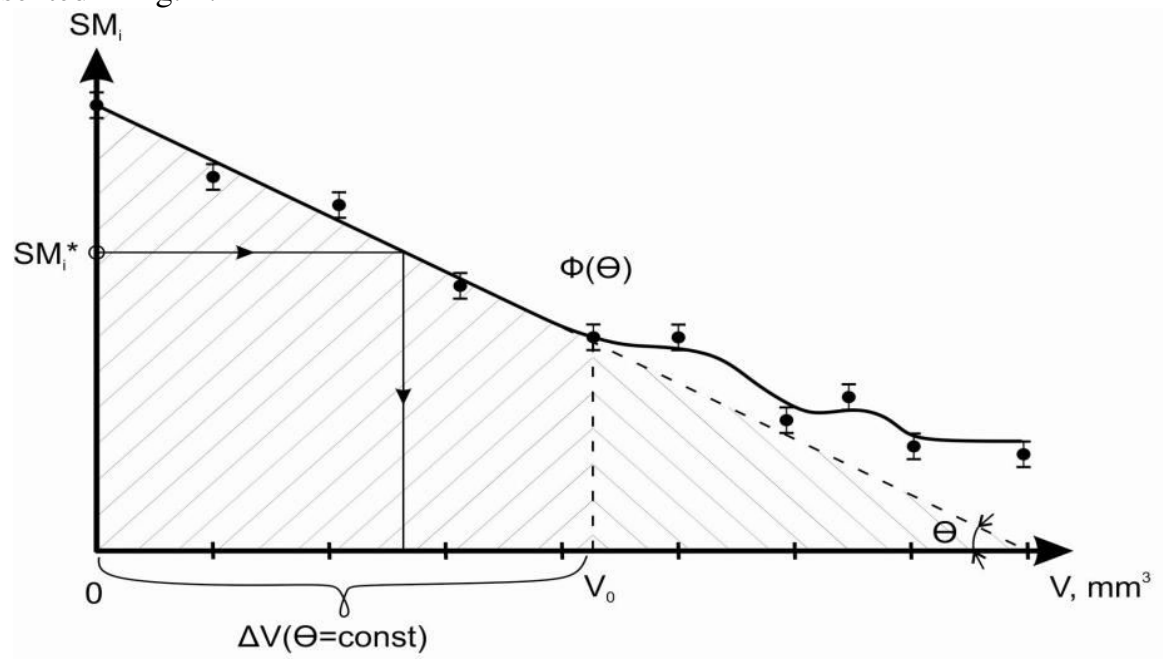

Fig. 4. Analytical scheme for determining the volume of blood loss of the dead according to the method of laser autofluorescence microscopy.

Table 2. Accuracy of determining the volume of blood loss in the spleen

\begin{tabular}{|c|c|c|c|c|c|}
\hline Blood loss, $\mathrm{mm}^{3}$ & $500 \pm 100 \mathrm{~mm}^{3}$ & $1000 \pm 100 \mathrm{~mm}^{3}$ & $1500 \pm 100 \mathrm{~mm}^{3}$ & $2000 \pm 100 \mathrm{~mm}^{3}$ & $2500 \pm 100 \mathrm{~mm}^{3}$ \\
\hline Average,$S M_{1}$ & 84 & 86 & 86 & 84 & 84 \\
\hline Dispersion, $S M_{2}$ & 94 & 94 & 92 & 92 & 90 \\
\hline Asymmetry, $S M_{3}$ & 96 & 94 & 94 & 92 & 90 \\
\hline Excess, $S M_{4}$ & 92 & 92 & 92 & 90 & 88 \\
\hline
\end{tabular}

Table 3. Accuracy of determining the volume of blood loss in the kidney

\begin{tabular}{|c|c|c|c|c|c|}
\hline Blood loss, $\mathrm{mm}^{3}$ & $500 \pm 100 \mathrm{~mm}^{3}$ & $1000 \pm 100 \mathrm{~mm}^{3}$ & $1500 \pm 100 \mathrm{~mm}^{3}$ & $2000 \pm 100 \mathrm{~mm}^{3}$ & $2500 \pm 100 \mathrm{~mm}^{3}$ \\
\hline Average,$S M_{1}$ & 96 & 96 & 96 & 94 & 94 \\
\hline Dispersion, $S M_{2}$ & 96 & 96 & 94 & 92 & 92 \\
\hline Asymmetry, $S M_{3}$ & 84 & 86 & 86 & 86 & 84 \\
\hline Excess, $S M_{4}$ & 94 & 94 & 92 & 90 & 90 \\
\hline
\end{tabular}

The analysis of the obtained data revealed the following parameters of the diagnostic efficiency ${ }^{15-26}$ of the statistical analysis of the results of the method of spectrally selective laser autofluorescence microscopy of histological sections of parenchymal biological tissues:

1. For all studied biological preparations, the range of sensitivity of the method of spectral-selective laser autofluorescence microscopy to changes in the volume of blood loss of the dead is the maximum level $0 \mathrm{~mm}^{3} \div 2500$ $\mathrm{mm}^{3}$. 
2. The accuracy of the method of spectral-selective laser autofluorescence microscopy of biological samples varies in the range: $\Delta V=0 \mathrm{~mm}^{3} \div 2500 \mathrm{~mm}^{3} \Leftrightarrow 86 \%-92 \%$;

3. The maximum level is reached for the following statistical parameters characterizing laser autofluorescence maps of histological sections of the kidney $-\left\{\begin{array}{l}S M_{1} \Leftrightarrow 94 \%-96 \% ; \\ S M_{2} \Leftrightarrow 94 \%-96 \% ; \\ S M_{4} \Leftrightarrow 90 \%-94 \% .\end{array}\right.$

\section{CONCLUSIONS}

1. A set of maps and histograms of random fluorescence intensity distributions of blood corpuscles of the polycrystalline component of histological sections of parenchymal biological tissues of the spleen and kidney of the deceased with varying degrees of blood loss were studied using spectral-selective laser autofluorescence microscopy.

2. The dynamics of changes in the magnitude of the statistical moments of the 1st - 4th orders, characterizing the distribution of MLA histological sections of parenchymal (kidney) tissues of the deceased with different blood loss $\Delta V=0 \mathrm{~mm}^{3} \div 2500 \mathrm{~mm}^{3}$, was studied.

3. The magnitudes and ranges of accuracy of the method of spectral-selective laser autofluorescent microscopy of biological preparations of the spleen are determined - $\left\{\begin{array}{l}S M_{1} \Leftrightarrow 94 \%-96 \% ; \\ S M_{2} \Leftrightarrow 94 \%-96 \% ; \\ S M_{4} \Leftrightarrow 90 \%-94 \% .\end{array}\right.$

\section{REFERENCES}

[1]. Wang X. Propagation of polarized light in birefringent turbid media: a Monte Carlo study / X. Wang, L.-H. Wang // J. Biomed. Opt. - 2002. - Vol. 7. - P. 279-290.

[2]. Tuchin V. V. Handbook of optical biomedical diagnostics / V. V. Tuchin. - Bellingham : SPIE Press, 2002. - 1110 p.

[3]. Yao G. Two-dimensional depth-resolved Mueller matrix characterization of biological tissue by optical coherence tomography / G. Yao, L. V. Wang // Opt. Lett. - 1999. - V. 24. - P. 537-539.

[4]. Tower T. T. Alignment Maps of Tissues: I. Microscopic Elliptical Polarimetry / T. T. Tower, R. T. Tranquillo // Biophys. J. - 2001. - Vol. 81. - P. 2954-2963.

[5]. Lu S. Interpretation of Mueller matrices based on polar decomposition / S. Lu, R. A. Chipman // J. Opt. Soc. Am. A. 1996. - Vol. 13. - P.1106-1113.

[6]. Ghosh Nirmalya. Techniques for fast and sensitive measurements of two-dimensional birefringence distributions / Nirmalya Ghosh, I. Alex Vitkin // Journal of Biomedical Optics. - 2011. - № 16(11). - P. 110801.

[7]. V. V. Tuchin, L. Wang, and D. A` Zimnyakov, Optical Polarization in Biomedical Applications, New York, USA (2006).

[8]. Angelsky, O.V., Hanson, S.G., Maksimyak, P.P., Maksimyak, A.P., Zenkova, C.Yu., Polyanskii, P.V., Ivanskyi, D.I., "Influence of evanescent wave on birefringent microplates," (2017) Optics Express, 25 (3), pp. 2299-2311.

[9]. 2. Angelsky, O.V., Ushenko, Y.A., Dubolazov, A.V., Telenha, O.Yu., "The interconnection between the coordinate distribution of mueller-matrixes images characteristic values of biological liquid crystals net and the pathological changes of human tissues,"(2010) Advances in Optical Technologies, art. no. 130659.

[10]. Bekshaev, A.Ya., Angelsky, O.V., Sviridova, S.V., Zenkova, C.Yu., "Mechanical action of inhomogeneously polarized optical fields and detection of the internal energy flows," (2011) Advances in Optical Technologies, art. no. 723901.

[11]. Angelsky, O.V., Maksimyak, P.P., Perun, T.O., "Optical correlation method for measuring spatial complexity in optical fields," (1993) Optics Letters, 18 (2), pp. 90-92.

[12]. Angelsky, O.V., Ushenko, A.G., Ushenko, Y.A., Pishak, V.P., "Statistical and fractal structure of biological tissue mueller matrix images," (2007) Optical Correlation Techniques and Applications, pp. 213-265.

[13]. Angelsky, O.V., Ushenko, A.G., Pishak, V.P., Burkovets, D.N., Yermolenko, S.B., Pishak, O.V., Ushenko, Yu.A., "Coherent introscopy of phase-inhomogeneous surfaces and layers," (2000) Proceedings of SPIE - The International Society for Optical Engineering, 4016, pp. 413-418. 
[14]. Angelsky, O.V., "Optical correlation techniques and applications,"(2007) Optical Correlation Techniques and Applications, pp. 1-270.

[15]. Angelsky, O.V., Maksimyak, P.P., "Optical diagnostics of slightly rough surfaces," (1992) Applied Optics, 31 (1), pp. 140-143.

[16]. Angelsky, O.V., Maksimyak, P.P., "Polarization-interference measurement of phase-inhomogeneous objects," (1992) Applied Optics, 31 (22), pp. 4417-4419.

[17]. Angelsky, O. V., Bekshaev, A. Ya., Maksimyak, P. P., Maksimyak, A. P., Hanson, Steen Grüner, "Low-temperature laser-stimulated controllable generation of micro-bubbles in a water suspension of absorptive colloid particles," Optics Express (2018), Vol. 26, No. 11. pp. 13995-14009.

[18]. Ushenko, Yu.A., Tomka, Yu.Ya., Dubolazov, A.V., Telen'ga, O.Yu. Diagnostics of optical anisotropy changes in biological tissues using Müller matrix (2011) Quantum Electronics, 41 (3), pp. 273-277.

[19]. Ushenko, Yu.A., Tomka, Yu.Ya., Dubolazov, A.V. Laser diagnostics of anisotropy in birefringent networks of biological tissues in different physiological conditions (2011) Quantum Electronics, 41 (2), pp. 170-175.

[20]. Ushenko, Y.A., Dubolazov, O.V., Karachevtsev, A.O. Statistical structure of skin derma Mueller matrix images in the process of cancer changes (2011) Optical Memory and Neural Networks (Information Optics), 20 (2), pp. 145-154.

[21]. Ushenko, V.A., Dubolazov, A.V. Correlation and self similarity structure of polycrystalline network biological layers mueller matrices images (2013) Proceedings of SPIE - The International Society for Optical Engineering, 8856, 88562D.

[22]. Ushenko, A.G., Dubolazov, A.V., Ushenko, V.A., Novakovskaya, O.Y. Statistical analysis of polarizationinhomogeneous Fourier spectra of laser radiation scattered by human skin in the tasks of differentiation of benign and malignant formations (2016) Journal of Biomedical Optics, 21 (7), 071110.

[23]. Ushenko, Y.A., Dubolazov, A.V., Angelsky, A.P., Sidor, M.I., Bodnar, G.B., Koval, G., Zabolotna, N.I., Smolarz, A., Junisbekov, M.S. Laser polarization fluorescence of the networks of optically anisotropic biological crystals (2013) Proceedings of SPIE - The International Society for Optical Engineering, 8698, 869809.

[24]. Angelsky, O. V., Ushenko, A. G., \& Ushenko, Y. A., "Polarization reconstruction of orientation structure of biological tissues birefringent architectonic nets by using their Mueller-matrix speckle-images," Journal of Holography and Speckle 2(2), $72-79$ (2005).

[25]. Angelsky, O. V., Yermolenko, S. B., Prydij, O., Ushenko, A. G., Ushenko, Y. A., \& Ushenko, Y. G., "Polarizationinterference structure of speckle fields of the rough skin surface," Journal of Holography and Speckle 3(1), 27-34 (2006).

[26]. V. A. Ushenko, N. I. Zabolotna, S. V. Pavlov, D. M. Burcovets, O. Yu. Novakovska, Olexander V. Dubolazov, "Mueller-matrices polarization selection of two-dimensional linear and circular birefringence images," Proc. SPIE 9066, Eleventh International Conference on Correlation Optics, 90661X (17 December 2013). 